\title{
RELATIONSHIP BETWEEN LEVEL OF EDUCATION AND POST-STROKE COGNITIVE STATUS IN HOSPITAL-BASED ISCHEMIC STROKE SURVIVORS
}

\author{
Herpan Syafii Harahap ${ }^{1}$, Yanna Indrayana ${ }^{2}$, Setyawati Asih Putri ${ }^{3}$ \\ Correspondence:herpanharahap@yahoo.co.id \\ ${ }^{I}$ Department of Neurology, Faculty of Medicine, Universitas Mataram, Mataram, Indonesia \\ ${ }^{2}$ Department of Cardiology, Faculty of Medicine, Universitas Mataram, Mataram, Indonesia \\ ${ }^{3}$ Department of Neurology Mataram General Hospital, Mataram, Indonesia
}

\section{Article History:}

Received: Agustus 5, 2019

Accepted: September 29, 2020

Published: January 1, 2021

\section{Cite this as:}

Harahap HS, Indrayana Y, Putri SA. Relationship between level of education and post-stroke cognitive status in hospital-based ischemic stroke survivors.

Malang Neurology Journal 2021.7:1-6.

http://dx.doi.org/10.21776/ub.mnj .2021 .007 .01 .1

\section{ABSTRACT}

Background: Post-ischemic stroke cognitive decline is significantly affecting the quality of life of its survivors. Its prevalence was about $7.5-72 \%$ which was mostly determined by the existing of vascular risk factors and cognitive reserve of the subjects. Level of education is one of determinants of cognitive reserve, a factor that affect the susceptibility of subjects to cognitive decline after experiencing ischemic stroke-related neuronal damage. Since level of education is protective for cognitive function, the intervention on it can reduce the occurrence of cognitive decline.

Objective: To investigate the relationship between level of education and cognitive status among hospital-based ischemic stroke survivors.

Methods: This cross-sectional study involved post-ischemic stroke outpatients in two hospitals. The data collected in this study were demographic data, including level of education, and clinical data as well. The level of education was categorized into $\geq 12$ years and $<12$ years groups. Cognitive status was assessed using Montreal Cognitive Assessment in Indonesia version (MoCA-Ina) and subjects with score of 26-30 were normal. The relationship between level of education as well as clinical data and cognitive status were analyzed using chi-square test.

Results: There were 166 subjects eligible for this study $(n=166)$. The mean age of subjects was 58 years and $68.67 \%$ of them were male. Cognitive decline were found $80.12 \%$ of subjects $(n=133)$. The level of education was significantly associated with cognitive status of the subjects and hypertension as well.

Conclusion: The level of education had significant relationship with cognitive decline in the hospitalbased population of ischemic stroke survivors.

Keywords: Post-ischemic stroke cognitive decline, level of education, cognitive reserve

\section{Introduction}

Cognitive decline is currently becoming an important complication of ischemic stroke. Post-stroke cognitive decline caused a significant decrease in quality of life and increase of mortality of the ischemic stroke survivors. ${ }^{1} \mathrm{~A}$ systematic review and meta-analysis conducted by Zulkifly et al. showed that the prevalence of cognitive decline among stroke survivors was about 7.5-72\%. ${ }^{2}$ Its prevalence was highest in the first year after onset of stroke. ${ }^{3}$ The wide range of its prevalence was mostly determined by several factors, including the population of the subjects, the time of the assessment of cognitive status, the instrument of the assessment of cognitive status used, the characteristics of vascular risk factors of the subjects, and cognitive reserve possessed by the subjects. $^{2}$

Cognitive reserve is a concept, besides brain reserve, which theoretically determines whether an individual is susceptible to cognitive decline after experiencing neuronal damage. ${ }^{4}$ In the context of ischemic stroke, the concept of cognitive reserve may account for the discrepancy between the extend of ischemic stroke-related neuronal damage and the cognitive status and/or the significant cognitive improvement among stroke survivors who have similar clinical conditions. Several factors recognized as the determinants of cognitive reserve are occupation, routine physical and social activities, and level of education.

The study focused on investigation of the significant relationship between level education as the representation of cognitive reserve and the occurrence of post-ischemic stroke cognitive decline has never been conducted, including in Indonesia. Most of previous studies were focused on the investigation of the significant relationship between well-identified vascular risk factors, including age, hypertension, diabetes mellitus, dyslipidemia, and atrial fibrillation, and decrease of cognitive status among stroke survivors. ${ }^{7,8,9}$ A cohort study conducted by Levine et al. in overall stroke survivors, both ischemic and haemorrhagic subtype of stroke, showed that low level of education was significantly decrease their cognitive status, prominently on executive domain. ${ }^{10}$ 
This was the first study conducted to investigate the significant relationship between level of education and cognitive status in ischemic stroke survivors. The ischemic stroke survivors included in this study represented hospitalbased population rather than community-based population.

\section{Methods}

This was a cross-sectional study involving all of ischemic stroke outpatients attending to two main referral hospital in West Nusa Tenggara, Mataram General Hospital and Mutiara Sukma Mental Hospital during period of January June 2019 after fulfilling the inclusion but not exclusion criteria. The inclusion criteria were subjects with prior history of ischemic stroke, literate, fully conscious, voluntary participated, and speaking in Indonesia Language. The exclusion criteria were previous diagnosis of pre-stroke cognitive impairment, the evidence of clinically significant depression, and aphasia and motor dysfunctions that interfere cognitive assessment. Subjects were considered to have clinically significant depression if the results of screening test of depression using Beck Depression Inventory-II (BDI-II) showed score of 1463. ${ }^{11,12}$ This study was conducted in January - June 2019. Written informed consent was obtained from all of the subjects. This study was conducted after getting approvement from Komisi Etik Penelitian Kesehatan Universitas Mataram with the ethical clearance number 401/UN18.F7/ETIK/2018.

The data collected in this study were demographic and clinical characteristics, level of education and cognitive status of the subjects. The demographic data of subjects consisted of age and gender. The clinical data of subjects consisted of stroke onset, location of lesion, hypertension, diabetes mellitus, dyslipidemia, and atrial fibrillation. The level of education was categorized into two groups, i.e $\geq 12$ years and $<12$ years according to previous studies. ${ }^{13,14}$ This categorization of level education was aimed to distinguish subjects with higher level of education ( $\geq 12$ years) and those with lower level of education ( $<12$ years), so that the relationship between level of education and cognitive status of these subjects could be analyzed. The instrument used in the assessment of cognitive status was Montreal Cognitive Assessment in Indonesia version (MoCA-Ina) scores ranged between 0-30. Based on this instrument, subjects with score of 26-30 were considered to have normal cognitive status, while those with score of 0-25 were considered to have cognitive impairment. ${ }^{15}$

The stroke onset was graded into four categories of time, i.e $\leq 3$ months, $>3$ to 12 months, $>12$ to 24 months, and $>24$ months. The location of lesion was determined by clinical examination and head CT scan results and categorized into two location, right and left hemispheres respectively. All clinical data of subjects were obtained from questionnaire and their medical records.

The data were presented as mean $(95 \% \mathrm{CI})$ unless otherwise stated. The relationship between level of education and cognitive status were analyzed using chi-square test. The association between clinical data and cognitive status was also analyzed using chi-square test. Statistical significance was set to be $\mathrm{p}<0.05$. All data was analyzed using a computer program.

\section{Results}

\section{Characteristics of the Subjects}

There were 191 ischemic stroke outpatients recruited at the baseline survey during January - July 2019 and 166 of them fulfilled the inclusion but not exclusion criteria $(n=166)$, as shown in Figure 1. These eligible subjects were obtained from Mataram General Hospital $(n=114)$ and Mutiara Sukma Mental Hospital $(n=52)$. The mean of age of the subjects was 58 years and $68.7 \%$ of them were male. The demographic and clinical data as well as level of education is presented in Table 1.

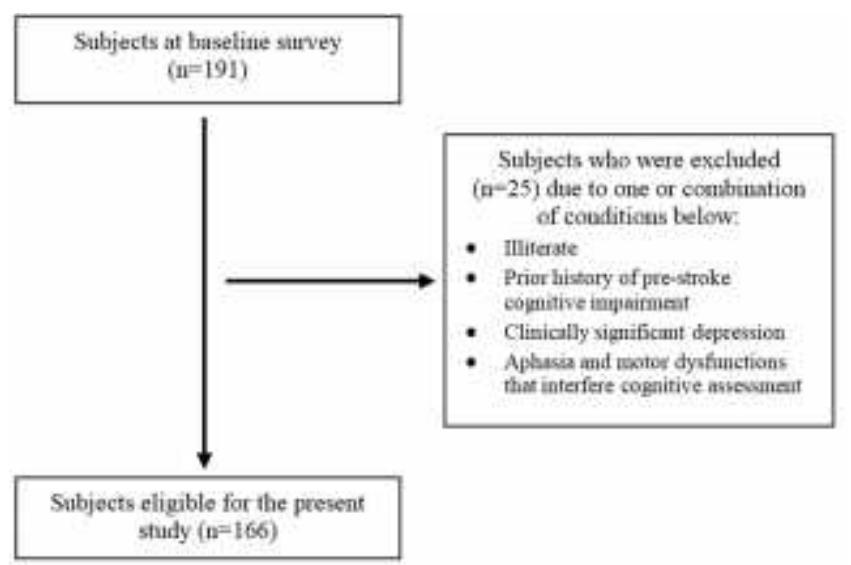

Figure 1. Diagram of subjects recruitment in the present study

The Association between Level of Education as well as Clinical Characteristics and Cognitive Status

Cognitive decline in this study were found $80.1 \%$ of the total subjects $(n=133)$. After grouping subjects into two groups, namely cognitive decline and normal cognitive status groups, level of education was significantly associated with cognitive function of the subjects and so was hypertension (Table 2).

\section{Discussion}

Cognitive decline among ischemic stroke survivors are now getting attention, since its prevalence is consistently quite high in several studies conducted in different population, either in community-based or hospital-based ischemic stroke survivors population. Epidemiologic studies conducted in several countries showed that the prevalence of post-ischemic stroke cognitive decline was in the range of $38-56.6 \% .^{16,17,18}$ Similar studies conducted in some regions of Indonesia, including Jakarta and Bandung using Montreal Cognitive Assessment in Indonesia version (MoCA-Ina) as cognitive assessment instrument, showed higher prevalence of post-ischemic stroke cognitive decline, in the range of $60.44-72 \% .{ }^{15,19}$ Consistent with the studies conducted in Jakarta and Bandung, the result of this study showed that its prevalence was about $80.1 \%$.

Not all of ischemic stroke patients will be suffered from cognitive decline. The vulnerability of the stroke survivors to be suffered from cognitive decline is mainly determined by the existing vascular risk factors. Previous studies, both 
Table1.Demographic and Clinical Characteristics of the Subjects

\begin{tabular}{|c|c|}
\hline Variables & $\begin{array}{l}\text { Mean }(95 \% \mathrm{CI}) \text {, unless otherwise stated } \\
\qquad(\mathrm{n}=166)\end{array}$ \\
\hline Age, years & $58,67(57.22-60.17)$ \\
\hline Male, n (\%) & $114(68.7)$ \\
\hline \multicolumn{2}{|l|}{ Level of education, $\mathrm{n}(\%)$} \\
\hline$<12$ years & $74(44.6)$ \\
\hline$\geq 12$ years & $92(55.4)$ \\
\hline \multicolumn{2}{|l|}{ Stroke onset, n (\%) } \\
\hline $\mathbf{s}$ months & $36(21.7)$ \\
\hline$>3-12$ months & $74(44.6)$ \\
\hline$>12-24$ months & $32(19.3)$ \\
\hline$>24$ months & $24(14.4)$ \\
\hline \multicolumn{2}{|l|}{ Location of lesion, n (\%) } \\
\hline Right hemisphere & $85(51.2)$ \\
\hline Left hemisphere & $81(48.8)$ \\
\hline Hypertension, n (\%) & $128(77.1)$ \\
\hline Diabetes mellitus, n (\%) & $37(22.3)$ \\
\hline Dyslipidemia, n (\%) & $85(51.2)$ \\
\hline Atrial fibrillation, n (\%) & $19(11.4)$ \\
\hline \multicolumn{2}{|l|}{ MoCA-Ina score, n (\%) } \\
\hline Normal (0-25) & $33(19.88)$ \\
\hline Cognitive decline (26-30) & $133(80.1)$ \\
\hline
\end{tabular}

MoCA-Ina=Montreal Cognitive Assessment in Indonesia version.

Table 2.The demographic and clinical characteristics between cognitive declineand normal cognitive status groups

\begin{tabular}{|c|c|c|c|}
\hline \multirow[b]{2}{*}{ Variables } & \multicolumn{2}{|c|}{ Cognitive Status } & \multirow[b]{2}{*}{ p-value } \\
\hline & $\begin{array}{c}\text { Cognitive Decline } \\
(n=133)\end{array}$ & $\begin{array}{c}\text { Normal } \\
(n=33)\end{array}$ & \\
\hline \multicolumn{4}{|l|}{ Gender, n (\%) } \\
\hline Male & $92(55.4)$ & $22(13.3)$ & 0.781 \\
\hline Female & $41(24.7)$ & $11(6.6)$ & \\
\hline \multicolumn{4}{|c|}{ Level of education, $n(\%)$} \\
\hline 12 years & $66(39.8)$ & $8(4.8)$ & $0.009 *$ \\
\hline$\geq 12$ years & $67(40.4)$ & $25(15.1)$ & \\
\hline \multicolumn{4}{|l|}{ Stroke onset, n (\%) } \\
\hline $\mathfrak{3}$ months & $32(19.3)$ & $4(2.4)$ & \\
\hline$>3-12$ months & $53(31.9)$ & $21(12.7)$ & 0.099 \\
\hline$>12-24$ months & $27(16.3)$ & $5(3.0)$ & \\
\hline$>24$ months & $21(12.7)$ & $3(1.8)$ & \\
\hline \multicolumn{4}{|c|}{ Location of lesion, $\mathrm{n}(\%)$} \\
\hline Right hemisphere & $66(39.8)$ & $19(11.4)$ & 0.413 \\
\hline Left hemisphere & $67(40.4)$ & $14(8.4)$ & \\
\hline \multicolumn{4}{|l|}{ Hypertension, n (\%) } \\
\hline Yes & $108(65.1)$ & $20(12.0)$ & $0.012 *$ \\
\hline No & $25(15.1)$ & $13(7.8)$ & \\
\hline \multicolumn{4}{|l|}{ Diabetes mellitus } \\
\hline Yes & $30(18.1)$ & $7(4.2)$ & 0.868 \\
\hline No & $103(62.0)$ & $26(15.7)$ & \\
\hline \multicolumn{4}{|l|}{ Dyslipidemia } \\
\hline Yes & $70(42.2)$ & $15(9.0)$ & 0.460 \\
\hline No & $63(38.0)$ & $18(10.8)$ & \\
\hline \multicolumn{4}{|l|}{ Atrial fibrillation, $n(\%)$} \\
\hline Yes & $17(10.2)$ & $2(1.2)$ & 0.371 \\
\hline No & $116(69.9)$ & 31 (18.7) & \\
\hline
\end{tabular}

original articles and systematic reviews, were more focused on the identification of the significant association of vascular risk factors of ischemic stroke and the prevalence of post-ischemic stroke cognitive decline. ${ }^{20,21,22}$ In general, vascular risk factors are divided into two main groups, nonmodifiable and modifiable risk factors respectively. Nonmodifiable risk factors consist of age, gender and ethnicity, while modifiable risk factors consist of hypertension, diabetes mellitus, dyslipidemia, and atrial fibrillation. ${ }^{23}$ In the pathophysiology of post-ischemic stroke cognitive decline, vascular risk factors mediate the occurrence of neurovascular unit dysfunction and cerebral blood flow dysregulation in certain brain regions serving particular cognitive functions, either independently or by their interaction with stroke event. ${ }^{7}$ Recent studies showed that age is the main predictor for the occurrence of postischemic stroke cognitive decline compared to the overall existing vascular risk factors. ${ }^{24}$ Among modifiable vascular risk factors, hypertension is the main predictor for the occurrence of post-ischemic stroke cognitive decline. ${ }^{25}$ In 
this study, among various vascular risk factors identified, only hypertension had a significant relationship with the decline of post-ischemic stroke cognitive status. This result indicated a significant consistency of the relationship between hypertension and the prevalence of post-ischemic stroke cognitive decline among recent studies. The proposed mechanisms underlying the role of hypertension in the development of post-ischemic stroke cognitive decline is the occurrence of hypertension-related small vessel disease and arterial stiffness resulting in both white matter and gray matter changes, especially in the prefrontal cortex, hippocampus, and inferior temporal cortex and inferior parietal lobule, the brain structures important in carrying out cognitive functions. ${ }^{26}$ The association between hypertension and post-ischemic stroke cognitive decline described above is strongly influenced by advancing age. ${ }^{27}$ Antihypertensive treatment is beneficial in reducing the risk of stroke and post-stroke cognitive decline. ${ }^{28}$

In addition to the existing vascular risk factors, the vulnerability of ischemic stroke survivors to be suffered from cognitive decline is also determined by their cognitive reserve status. The concept of cognitive reserve explains how an ischemic stroke survivor is able to perform a certain cognitive task properly and in flexible manner even though there is some degree of stroke-related brain dysfunction in certain areas that carry out this cognitive function. ${ }^{29}$ In this case, the concept of cognitive reserve can be proposed to explain the incompatibility of the relationship between the degree of ischemic stroke-related neuronal damage and the decline in cognitive status among ischemic stroke survivors. $^{30}$ In such condition, there is a neural compensation in which ischemic stroke-related neuronal damage in certain brain areas that serve specific cognitive functions will lead to recruitment as well as activation of compensatory networks that normally play an important role as a secondary area carrying out those specific cognitive functions. ${ }^{31}$ This neural compensation can explain the differences in clinical outcomes of post-ischemic stroke cognitive decline as well as the effectiveness in its recovery process among ischemic stroke survivors. The complexity of neural compensation itself, which describes the concept of cognitive reserve, is determined by life experiences of a subject in working on a particular cognitive task which was obtained mainly through formal education, occupation, and daily physical as well as social activities prior ischemic stroke event. $^{5}$

Recent studies have shown that level of education is a representation of the concept of cognitive reserve which has significant relationship with cognitive status in elderly population and Alzheimer's disease patients. ${ }^{5,32,33,34}$ The study aimed to investigate the impact of low level of education to cognitive status among stroke survivors regardless to stroke subtype are still very limited and have not been conducted specifically in ischemic stroke subtype patients. A cohort study conducted by Levine et al. have shown that low level of education significantly decrease the cognitive status of both ischemic and haemorrhagic stroke survivors, prominently on executive domain. ${ }^{10}$ This was the first study focused on investigating the relationship between level of education and cognitive status in ischemic stroke outpatients representing hospital-based population. This study revealed that there was a significant relationship between the level of education and cognitive status in those population. This result indicated that level of education, beside hypertension, was an important risk factor for the decline in the post-ischemic stroke cognitive status in those subjects. As noted earlier, level of education as one of the determinants of cognitive reserve also played an important role in determining the successful of neural compensation mechanism which favor either in maintaining the cognitive status to remain intact or in accelerating the healing process of cognitive status among ischemic stroke survivors. ${ }^{31}$ Therefore, level of education is a better indicator of brain capacity to compensate for pathology efficiently either using the existing cognitive networks or recruiting the alternative networks. ${ }^{5}$ Alternatively, stroke survivors with higher level of education generally have better lifestyle and adherence to treatment and this might explain the better cognitive status of stroke survivors in this group compared to group of stroke survivors with lower level of education. ${ }^{35}$

The limitation of this study was that it did not identify the relationship between cognitive reserve determinants other than level of education, including recent occupation as well as the intensity of daily physical and social activities. Therefore, the significance relationship of level of education and cognitive status in this study could only represent the role of cognitive reserve partially. The heterogeneity of the subjects and their recall of detailed process of the occupation as well as the intensity of actual daily physical and social activities prior ischemic stroke event which were poorly documented. So, it made an obstacle in the analysis of the relationship between cognitive reserve status as a whole and cognitive status among ischemic stroke survivors. Therefore, a cohort study with systematic recording of the intensity of the occupation as well as the intensity of actual daily physical and social activities in those subjects in order to generalize their relationship to cognitive status is mandatory.

\section{Conclusion}

In conclusion, the level of education as a representation of cognitive reserve had a significant relationship with the decline of post-ischemic stroke cognitive status in the hospital-based population of ischemic stroke survivors. A cohort study is mandatory to identify the role of education, occupation and the intensity of routine physical and social activities on cognitive status among ischemic stroke survivors so that the role of cognitive reserve as a whole can be generalized in compensating the decline of cognitive status in this population. In addition, hypertension was consistently still having significant relationship with the decline of cognitive status among this population, regarding to previous studies.

\section{Acknowledgement}

We would like to acknowledge the contribution of Made Rika Anastasia Pratiwi and Hardinata.

\section{References}

1. Melkas S, Jokinen H, Hietanen M, Erkinjuntti T. Poststroke cognitive impairment and dementia: 
2. prevalence, diagnosis, and treatment. Degener Neurol Neuromuscul Dis; 2014. 4:21-7. DOI: http://dx.doi.org/10.2147/DNND.S37353.

3. Zulkifly MFM, Ghazali SE, Din NC, Singh DKA, Subramaniam P. A Review of Risk Factors for Cognitive Impairment in Stroke Survivors. Sci World J; 2016. 2016:3456943.

DOI: http://dx.doi.org/10.1155/2016/3456943.

4. Sun J-H, Tan L, Yu J-T. Post-stroke cognitive impairment: epidemiology, mechanisms, and management. Ann Transl Med; 2014. 2(8):80.

DOI: 10.3978/j.issn.2305-5839.2014.08.05.

5. Steffener J, Stern Y. Exploring the neural basis of cognitive reserve in aging. Biochim Biophys Acta; 2012. 1822(3):467-73.

DOI: http://dx.doi.org/10.1016/j.bbadis.2011.09.012

6. Darwish H, Farran N, Assaad S, Chaaya M. Cognitive reserve factors in a developing country: Education and occupational attainment lower the risk of dementia in a sample of lebanese older adults. Front Aging Neurosci; 2018. 10:277.

DOI: $10.3389 /$ fnagi.2018.00277.

7. Agoes A, Lestari R, Alfaruqi S. Effects of brain age to increase cognitive function in elderly. MNJ; 2016. 2(2):64-70.

DOI: 10.21776/ub.mnj.2016.002.02.4

8. Gorelick PB, Scuteri A, Black SE, DeCarli C, Greenberg SM, Iadecola C, et al. Vascular Contributions to Cognitive Impairment and Dementia: A Statement for Healthcare Professionals From the American Heart Association/American Stroke Association. Stroke; 2011. 42(9):2672-713. DOI: 10.1161/STR.0b013e3182299496.

9. Faizal M, Zulkifly M, Ghazali SE, Din NC, Kaur D, Singh A, et al. A Review of Risk Factors for Cognitive Impairment in Stroke Survivors. Sci World J; 2016. 2016:3456943. DOI: http://dx.doi.org/10.1155/2016/3456943

10. Munir B, Al Rasyid H, Rosita R. Relationship between The Random Blood Glucose Levels During Admission at Emergency Room with Clinical Output in Acute Ischemic Stroke Patients. MNJ; 2015. 1(2):52-60.

DOI: 10.21776/ub.mnj.2015.001.02.2

11. Levine DA, Wadley VG, Langa KM, Howard G, Howard VJ, Cushman M. Risk factors for post-stroke cognitive decline: The REGARDS study. Stroke; 2018. 49(4):987-94.

DOI: 10.1161/STROKEAHA.117.018529

12. Jackson-Koku G. Beck depression inventory. Occup Med (Chic Ill); 2016. 66:174-5.

DOI: $10.1093 /$ occmed/kqv087

13. Wang Y-P, Gorenstein C. Assessment of depression in medical patients : A systematic review of the utility of the Beck Depression Inventory-II. Clinics; 2013. 68(9):1274-87.

DOI: 10.6061/clinics/2013(09)15

14. Crowe M, Clay OJ, Martin RC, Howard VJ, Wadley VG, Sawyer P, et al. Indicators of childhood quality of education in relation to cognitive function in older adulthood. J Gerontol A Biol Sci Med Sci; 2013. 68(2):198-204. DOI: 10.1093/gerona/gls122
15. Aminov A, Rogers JM, Johnstone SJ, Middleton S, Wilson $\mathrm{H}$. Acute single channel EEG predictors of cognitive function after stroke. PLoS One; 2017. 12(10):e0185841.

DOI: http://dx.doi.org/10.1371/journal.pone.0185841

16. Lestari S, Mistivani I, Rumende C, Kusumaningsih W. Comparison between mini mental state examination (MMSE) and Montreal cognitive assessment Indonesian version (MoCA-Ina) as an early detection of cognitive impairments in post-stroke patients. J Phys Conf Ser; 2017. 884:012153.

DOI: 10.1088/1742-6596/884/1/012153

17. Mellon L, Brewer L, Hall P, Horgan F, Williams D, Hickey A. Cognitive impairment six months after ischaemic stroke : a profile from the ASPIRE-S study. BMC Neurol; 2015. 2015:31. DOI: 10.1186/s12883015-0288-2

18. Barbay M, Diouf M, Roussel M, Godefroy O. Systematic review and meta-analysis of prevalence in post-stroke neurocognitive disorders in hospital-based studies. Dement Geriatr Cogn Disord; 2018. 46:32234. DOI: $10.1159 / 000492920$

19. Sexton E, Mcloughlin A, Williams DJ, Merriman NA, Donnelly N, Rohde D, et al. Systematic review and meta-analysis of the prevalence of cognitive impairment no dementia in the first year post-stroke. Eur Stroke J. 2019;4(2):160-71.

DOI: $10.1177 / 2396987318825484$

20. Nurani RRS, Martini S. Risk factors for cognitive impairment after ischemic stroke. KnE Life Sci; 2018. 2018:87-96. DOI: 10.18502/kls.v4i9.3560

21. Ihle-Hansen H, Thommessen B, Fagerland MW, Øksengård $\mathrm{AR}$, Wyller $\mathrm{TB}$, Engedal $\mathrm{K}$, et al. Multifactorial vascular risk factor intervention to prevent cognitive impairment after stroke and TIA : A 12-month randomized controlled trial. Int J Stroke; 2014. 9:932-8. DOI: $\quad 10.1111 / \mathrm{j} .1747-$ 4949.2012.00928.x

22. Surawan J, Areemit S, Tiamkao S, Sirithanawuthichai T, Saensak S. Risk factors associated with post-stroke dementia: a systematic review and meta-analysis. Neurol Int; 2017. 9:7216. DOI: 10.4081/nir.2017.7216.

23. Mijajlovic MD, Pavlovic A, Brainin M, Heiss W, Quinn TJ, Ihle-hansen HB, et al. Post-stroke dementia: A comprehensive review. BMC Med; 2017. 15(1):11. DOI: 10.1186/s12916-017-0779-7

24. Peters R, Booth A, Rockwood K, Peters J, Este CD, Anstey KJ. Combining modifiable risk factors and risk of dementia: a systematic review and meta-analysis. BMJ Open; 2019. 9:E022846. DOI:10.1136/bmjopen2018-022846

25. Kalaria RN, Akinyemi R, Ihara M. Stroke injury , cognitive impairment and vascular dementia. BBA Mol Basis Dis; 2016. 1862(5):915-25.

DOI: http://dx.doi.org/10.1016/j.bbadis.2016.01.015

26. Sharp SI, Aarsland D, Day S, Sønnesyn H. Hypertension is a potential risk factor for vascular dementia : Systematic review. Int J Geriatr Psychiatry; 2011. 26:661-9. DOI: 10.1002/gps.2572

27. Tadic M, Cuspidi C, Hering D. Hypertension and cognitive dysfunction in elderly: blood pressure 
management for this global burden. BMC Cardiovasc Disord; 2016. 16:208.

DOI: http://dx.doi.org/10.1186/s12872-016-0386-0

28. Dariusz G, Kwarciany M, Nyka W, Narkiewicz K. Hypertension, Brain Damage and Cognitive Decline. Curr Hypertens Rep; 2013. 15:547-58. DOI 10.1007/s11906-013-0398-4

29. Sörös P, Whitehead S, Spence JD, Hachinski V. Antihypertensive treatment can prevent stroke and cognitive decline. Nat Rev Neurol; 2013. 9(3):174-8. DOI: $10.1038 /$ nrneurol.2012.255

30. Stern Y. Cognitive Reserve: Implications for assessment and intervention. Folia Phoniatr Logop; 2013. 65(2):49-54. DOI: 10.1159/000353443

31. Umarova RM. Adapting the concepts of brain and cognitive reserve to post-stroke cognitive deficits: Implications for understanding neglect. Cortex; 2017. 97:327-38.

DOI: http://dx.doi.org/10.1016/j.cortex.2016.12.006

32. Barulli D, Stern Y.d Efficiency, capacity, compensation, maintenance, plasticity: emerging concepts in cognitive reserve. Trends Cogn Sci; 2013. 17(10):502-9. DOI: 10.1016/j.tics.2013.08.012

33. Wang Y, Du Y, Li J, Qiu C. Lifespan intellectual factors, genetic susceptibility, and cognitive phenotypes in aging: Implications for interventions. Front Aging Neurosci; 2019. 11:129. DOI: $10.3389 /$ fnagi.2019.00129

34. Jung N-Y, Cho H, Kim YJ, Kim HJ, Lee JM, Park S, et al. The impact of education on cortical thickness in amyloid-negative subcortical vascular dementia: cognitive reserve hypothesis. Alzheimer's Res Ther; 2018. 10:103. DOI: 10.1186/s13195-018-0432-5

35. Farfel JM, Nitrini R, Suemoto CK, Grinberg LT, Lucena RE, Paraizo RE, et al. Very low levels of education and cognitive reserve: A clinicopathologic study. Neurology; 2013. 81:650-7.

DOI: 10.1212/WNL.0b013e3182a08f1b

36. Mirza SS, Portegies MLP, Wolters FJ, Hofman A, Koudstaal PJ, Tiemeier H, et al. Higher education is associated with a lower risk of dementia after a stroke or TIA . The Rotterdam Study. Neuroepidemiology; 2016. 46:120-7. DOI: 10.1159/000443649 